\title{
Patient and Healthcare Professional Satisfaction Ratings and Safety Profile of Sufentanil Sublingual Tablets for Treatment of Acute Pain: A Pooled Demographic Analysis
}

This article was published in the following Dove Press journal:

Journal of Pain Research

\author{
David Leiman ${ }^{1,2}$ \\ Maurice Jové ${ }^{3}$ \\ Gail Rosen Spahn ${ }^{4}$ \\ Pamela Palmer ${ }^{4}$ \\ 'HD Research, Houston, TX, USA; \\ ${ }^{2}$ University of Texas at Houston, \\ Department of Surgery, Houston, TX, \\ USA; ${ }^{3}$ Atlanta Bone and Joint Specialists, \\ Atlanta, GA, USA; ${ }^{4}$ Medical Affairs, \\ AcelRx Pharmaceuticals, Inc, Redwood \\ City, CA, USA
}

Objective: This analysis reports the healthcare professional global assessment (HPGA) and patient global assessment (PGA) scores and the adverse event (AE) profile by age, body mass index (BMI), sex, and race from the three Phase III registration studies for sufentanil sublingual tablet (SST) $30 \mathrm{mcg}$.

Methods: Global assessments and treatment-related AEs were analyzed from patients treated with SST $30 \mathrm{mcg}$ for moderate-to-severe acute pain following surgery or in the emergency department (ED). Pooled data were analyzed across patient demographic subgroups.

Results: A total of 283 patients were included in the HPGA/PGA analyses. The majority underwent abdominal surgery, with the remaining patients undergoing orthopedic or "other" types of surgery. Overall, SST $30 \mathrm{mcg}$ was highly rated by both healthcare professionals and patients across the demographic subgroups. A total of 323 patients were included in the safety evaluation. The majority of patients did not experience any SST-related AEs; however, those that did experienced common opioid-related side effects such as nausea, headache, dizziness, and vomiting. No patients experienced unexpected AEs or required the use of naloxone.

Conclusion: SST $30 \mathrm{mcg}$ was highly rated and well tolerated across demographic subgroups with the majority of patients not experiencing any adverse event related to SST 30 mcg. These findings support the use of sublingual sufentanil in all adult patients, regardless of age, BMI, sex, or race for the treatment of moderate-to-severe acute pain.

Keywords: acute pain, demography, global assessment, sublingual administration, sufentanil, surgery

\section{Introduction}

Inadequate pain management in the postsurgical or emergency department (ED) setting can result in increased hospital stays, longer stays in the post-anesthesia care unit (PACU) or ED, poor patient satisfaction, and poor long-term outcomes. ${ }^{1-3}$ To date, effective management of moderate-to-severe acute pain in a medically supervised setting, whether following a surgical procedure or in the ED, commonly incorporates the use of intravenous (IV) opioids, commonly morphine or hydromorphone, given the slow onset of action of oral pain relievers. ${ }^{4,5}$ While relatively faster in onset than the oral route, IV morphine and, to a lesser extent, IV hydromorphone have slow blood:brain equilibration half-lives and active glucuronide metabolites, which can lead to dose-stacking and the risk of cognitive impairment
Correspondence: David Leiman Email leimanmd@gmail.com
Journal of Pain Research 2021:14 805-813

805 
and/or respiratory depression - especially in elderly patients or patients with renal or hepatic impairment. ${ }^{6-8}$ Due to the adverse event profile of these drugs, IV fentanyl may often be considered preferable to morphine and hydromorphone, especially in short-term care settings, such as the ED, operating room, or PACU. Fentanyl is lipophilic, has a rapid blood:brain equilibration half-life and no active metabolites. ${ }^{9,10}$ These properties result in a rapid onset of action following IV administration; however, fentanyl has a very fast distribution $(1.7 \mathrm{~min})$ and redistribution (13 $\mathrm{min}$ ) half-life, resulting in the need for frequent redosing of the drug. ${ }^{11}$

Sufentanil, a fentanyl analog, has the highest therapeutic index (ratio of lethal dose to effective dose) of the commonly used opioids, and, compared to fentanyl, has been shown to cause less respiratory depressive effects and possibly less cognitive dysfunction. ${ }^{12-15}$ Sufentanil is more than twice as lipophilic as fentanyl and has rapid blood:brain equilibration and no active metabolites, but also suffers from a rapid offset of effect when administered IV due to its distribution half-life of 1.4 minutes and redistribution half-life of $17 \mathrm{~min}^{9,16,17}$ Therefore it appears as an ideal opioid for management of acute pain in medically supervised settings if the duration of action could be prolonged.

Sufentanil sublingual tablet $30 \mathrm{mcg}$ (SST; DSUVIA ${ }^{\circledR}$; AcelRx Pharmaceuticals Inc., Redwood City, CA) was developed to leverage the positive attributes of sufentanil to provide rapid, non-invasive relief of moderate-to-severe acute pain in a hospital, ambulatory surgery center or other medically supervised setting. ${ }^{18}$ The sublingual route of administration results in a 17 -fold lower mean $\mathrm{C}_{\max }$ compared with IV sufentanil administration. ${ }^{19}$ Importantly, the sublingual route also prolongs the mean plasma half-time (time from $\mathrm{C}_{\max }$ to $50 \%$ of $\mathrm{C}_{\max }$ ) from 0.2 to 2.5 hours. ${ }^{19,20}$ This unique pharmacokinetic profile provides pain relief within 15 minutes that lasts for up to three hours. ${ }^{21}$ Prior to FDA-approval in November 2018, SST $30 \mathrm{mcg}$ was evaluated in three Phase III studies which showed significant reductions in acute pain following surgery and in the ED with no cases of respiratory depression requiring naloxone or unexpected non-opioid-related side effects. $^{21-23}$ Previous publications have reported the pooled pain intensity results and safety profiles across these studies. ${ }^{24,25}$ Since adverse events associated with opioid administration and patient's and healthcare professional's satisfaction with pain control may vary by patient demographic, it is important to analyze these outcomes based on demographic subpopulations. The current study contains a pooled analysis across the three Phase III studies of SST $30 \mathrm{mcg}$ of the healthcare professional global assessment (HPGA) and patient global assessment (PGA) scores and the adverse event (AE) profile by age, body mass index (BMI), sex, and race.

\section{Methods}

\section{Study Design}

HPGA, PGA, and safety data for these analyses were pooled from three Phase III clinical studies for SST 30 mcg (SAP301/NCT02356588, SAP302/NCT02447848, and SAP303/NCT02662556). In each study, SST $30 \mathrm{mcg}$ was administered to patients with acute pain who were classified as American Society of Anesthesiologists (ASA) Class I-III; 52\% were classified as ASA II or III (eg, had at least one comorbidity). ${ }^{25}$ All patients were non-opioid tolerant, taking $\leq 15 \mathrm{mg}$ oral morphine milligram equivalents (MME) daily within the previous three months. SST 30 mcg was administered via a prefilled single-dose applicator as needed, but no more than once per hour. The full study designs of these clinical trials have been described previously; but briefly, SAP301 ( $\mathrm{n}=107$ SST-dosed patients) was a multi-center, randomized, double-blind, placebo-controlled study, up to 48-hour duration, in adults after abdominoplasty, open tension-free inguinal hernioplasty, or laparoscopic abdominal surgery. ${ }^{21}$ SAP302 ( $=$ 76) was a multi-center, single-arm, open-label study up to 5-hour duration, in adults who presented to the emergency department with moderate-to-severe pain due to obvious trauma or injury. ${ }^{23}$ SAP303 $(n=140)$ was a multi-center, single-arm, open-label study of 12-hours duration, in patients aged 40 years or older after a variety of surgeries. ${ }^{22}$

As prespecified secondary endpoints in each study, HPGA and PGA were reported by the healthcare professional (mainly nurses) and patient, respectively, on a 4-point scale where the method of pain control was rated as poor, fair, good, or excellent. HPGA and PGA questionnaires were administered at the time of initial study completion (24-hours (SAP301), 2-hours (SAP302), and 12-hours (SAP303), or at early termination. An initial cohort of 40 patients in the SAP302 study were allowed only a single SST $30 \mathrm{mcg}$ dose and 2-hour PGA or HPGA were not performed, however these patients are included in the safety analysis. Treatment-related AEs, defined as possibly or probably related to the study medication by the 
investigators, were monitored throughout the studies and for 12-hours after the last dose of study drug. For this analysis, HPGA, PGA, and treatment-related AEs (occurring in at least $1 \%$ of patients) were analyzed across the prespecified demographic subgroups of age ( $<65$ vs $\geq 65$ years), BMI $\left(<30 \mathrm{~kg} / \mathrm{m}^{2}\right.$ vs $\left.\geq 30 \mathrm{~kg} / \mathrm{m}^{2}\right)$, sex, and race. Statistical differences in groups were evaluated based on Cochran-MantelHaenszel test of general association with modified ridit scores for the global assessments and on a two-sided Fisher's exact test for AEs.

\section{Results}

\section{Patient Disposition and Surgery Type}

For the HPGA and PGA, a total of 283 patients from the three phase III studies completed the assessments and were included in this analysis (Table 1). The majority of patients were less than 65 years of age, had BMIs less than $30 \mathrm{~kg} / \mathrm{m}^{2}$, were female, and white. When surgery type was evaluated within the BMI, sex, and race groups, the majority of all patients underwent abdominal procedures $(60-73 \%)$, with fewer classified as orthopedic surgery $(11-19 \%)$, and the rest as other (7-26\%). The only demographic that underwent a relatively higher percentage of non-abdominal surgeries was the older patients; in patients 65 years or older, approximately half (48\%) of surgeries were orthopedic in nature, whereas most surgeries were abdominal in younger patients $(70 \%)$.

Table I Demographics by Surgery Type

\begin{tabular}{|l|c|c|c|}
\hline Demographics (n; \%) & $\begin{array}{c}\text { Orthopedic } \\
(\mathbf{n})\end{array}$ & $\begin{array}{c}\text { Abdominal } \\
(\mathbf{n})\end{array}$ & $\begin{array}{c}\text { Other } \\
(\mathbf{n})\end{array}$ \\
\hline Age & 27 & 178 & 51 \\
$<65(\mathrm{n}=256 ; 90 \%)$ & 13 & 12 & 2 \\
$\geq 65(\mathrm{n}=27 ; 10 \%)$ & 19 & 119 & 39 \\
\hline BMI & 20 & 71 & 12 \\
$<30 \mathrm{~kg} / \mathrm{m}^{2}(\mathrm{n}=177 ; 63 \%)$ & & & \\
$\geq 30 \mathrm{~kg} / \mathrm{m}^{2}(\mathrm{n}=103 ; 37 \%)$ & 18 & 89 & 19 \\
\hline Sex & 22 & 101 & 34 \\
Male $(n=126 ; 45 \%)$ & & & \\
Female $(n=157 ; 55 \%)$ & 31 & 147 & 37 \\
\hline Race & 7 & 32 & 14 \\
White $(n=215 ; 76 \%)$ & & & \\
Black or African American & 11 & 2 \\
$\quad(n=53 ; 19 \%)$ & 2 & 1 & \\
Other $(n=15 ; 5 \%)$ & &
\end{tabular}

\section{Global Assessments of the Method of Pain Control}

Regardless of age, BMI, sex or race, global assessments of the method of pain control were highly rated by healthcare professionals and patients throughout the Phase III studies. Overall, there were no statistically significant differences between the HPGA or PGA scores in younger versus older subjects (Figure 1). The highest HPGA rating throughout the studies was for the "excellent" pain control category for elderly patients $(61 \%)$, with only $4 \%$ of the elderly patients rated as having "poor" pain control. For the top two combined rating categories of good or excellent pain control, healthcare professionals rated $87 \%$ of patients $<65$ years of age as having good or excellent pain control relative to $83 \%$ of patients $\geq 65$ years. A similar trend was observed in the patient global assessments with $86 \%$ of patients $<65$ years rating the method of pain control as good or excellent compared with $78 \%$ in patients $\geq 65$ years of age.

Importantly, as sufentanil is a highly lipophilic drug, there were no significant differences between healthcare professional or patient global assessment scores in patients with a BMI of $<30 \mathrm{~kg} / \mathrm{m}^{2}$ versus obese patients with BMIs $\geq 30 \mathrm{~kg} / \mathrm{m}^{2}$ (Figure 2). HPGA scores for good or excellent were $86 \%$ versus $89 \%$ and PGA scores for good or excellent were $86 \%$ versus $85 \%$ for BMIs $<30 \mathrm{~kg} / \mathrm{m}^{2}$ versus BMIs $\geq 30 \mathrm{~kg} / \mathrm{m}^{2}$, respectively.

While HPGA ratings were generally high for both sexes, statistically they were higher overall for male versus female patients (Figure 3). Global assessment of the method of pain control was rated as good or excellent for $92 \%$ of males compared to $81 \%$ of females. Although this trend continued for patient-rated global scores, there was no statistical difference in PGA scores between males and females.

Race had no significant effect on HPGA or PGA scores (Figure 4). There were numerically slightly higher HPGA and PGA scores for White patients and patients who identified as Other (American Indian, Alaska Native, or Asian) relative to Black/African American patients; HPGA and PGA ratings of good or excellent were greater than $85 \%$ for White and Other patients compared 72\% (HPGA) and $75 \%$ (PGA) in Black/African American patients.

\section{Adverse Events}

In this pooled analysis, 323 patients were included in the safety evaluation (eg, any patient that received at least one dose of SST $30 \mathrm{mcg}$ regardless of whether they completed 


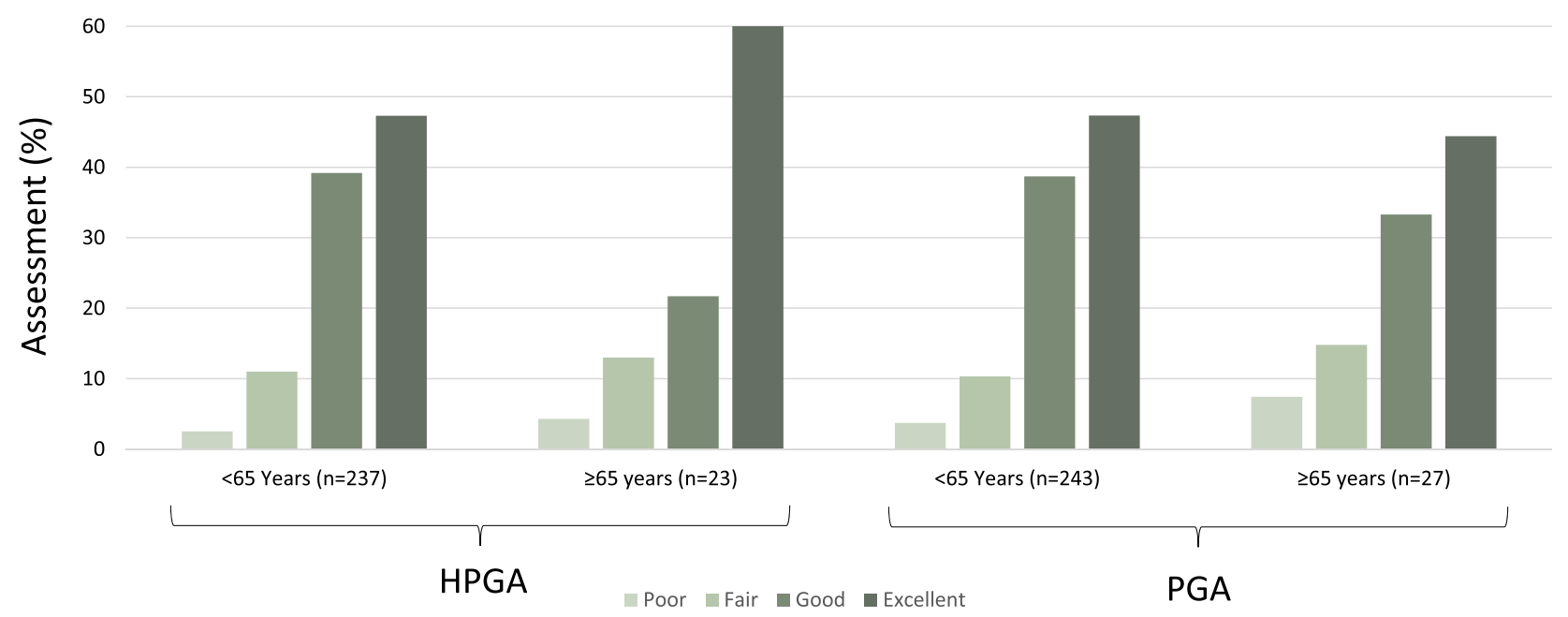

HPGA = healthcare professional global assessment; PGA = patient global assessment; there were no significant differences between groups for HPGA or PGA

Figure I Effect of age on HPGA and PGA.

Note: There were no significant differences between groups for HPGA or PGA.

Abbreviations: HPGA, healthcare professional global assessment; PGA, patient global assessment.

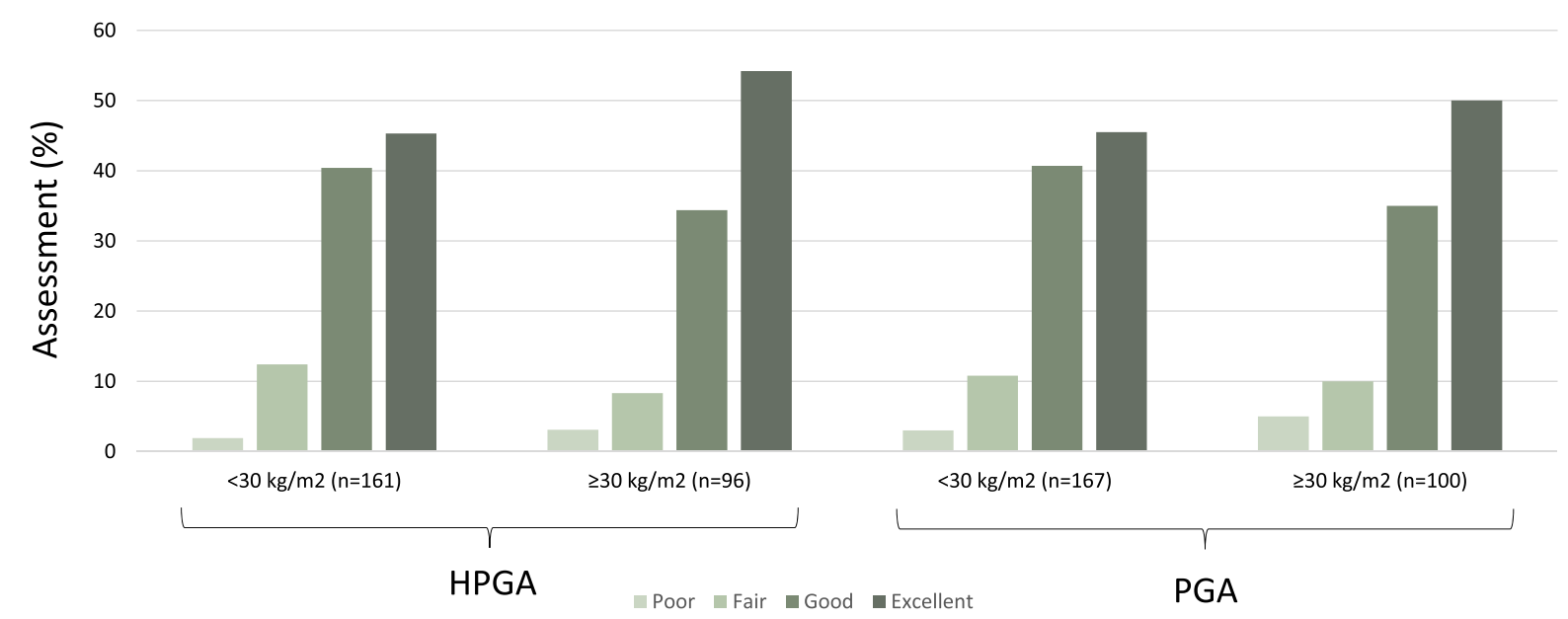

$\mathrm{BMI}=$ body mass index; HPGA = healthcare professional global assessment; PGA = patient global assessment; there were no significant differences between groups for HPGA or PGA

Figure 2 Effect of BMI on HPGA and PGA.

Note: There were no significant differences between groups for HPGA or PGA.

Abbreviations: BMI, body mass index; HPGA, healthcare professional global assessment; PGA, patient global assessment.

the study). SST 30 mcg was well-tolerated across patients, with $68 \%$ of all subjects not experiencing any SST-related adverse event (Tables 2-5). Of adverse events reported in $\geq 2 \%$ of patients, nausea was most common $(22.9 \%$ ), followed by patients experiencing headache (5.0\%), dizziness (4.0\%) and vomiting (3.1\%), all of which are consistent with the well-established side effect profile associated with opioid administration, and are commonly observed following surgery. Importantly, rates of decreased oxygen saturation (1.5\%) and somnolence (1.2\%) were low throughout the Phase III studies.

Within the demographic groups, treatment-related adverse events were similar with the exception of increases in dizziness in patients $\geq 65$ yrs old (Table 2), headaches in patients $<30 \mathrm{~kg} / \mathrm{m}^{2}$ (Table 3), and nausea, headaches, dizziness, pruritus, and hypotension in females (Table 4). There were no clear differences in safety or tolerability between the different races (Table 5). 


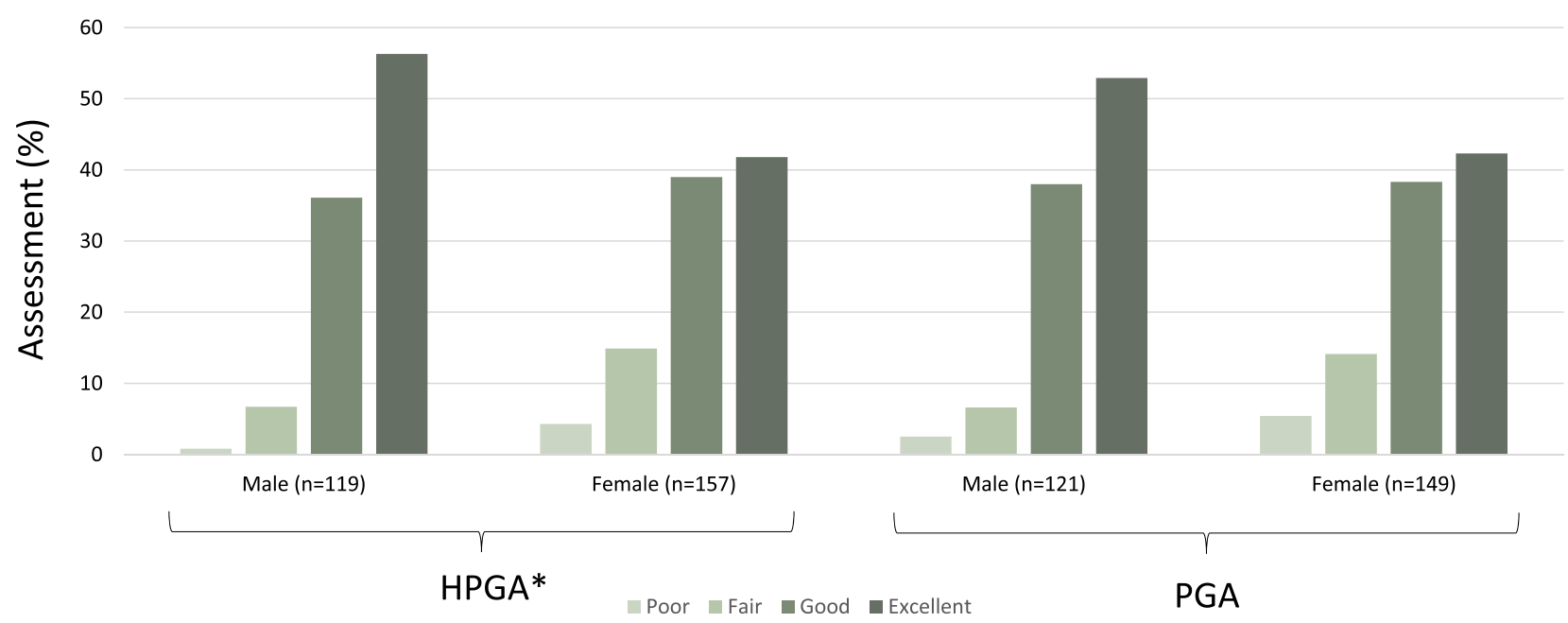

HPGA = healthcare professional global assessment; $P G A=$ patient global assessment; ${ }^{*} \mathrm{P}=.023$; there were no significant differences between groups for $\mathrm{PGA}$

Figure 3 Effect of sex on HPGA and PGA.

Notes: $* P=0.023$; there were no significant differences between groups for PGA.

Abbreviations: HPGA, healthcare professional global assessment; PGA, patient global assessment.

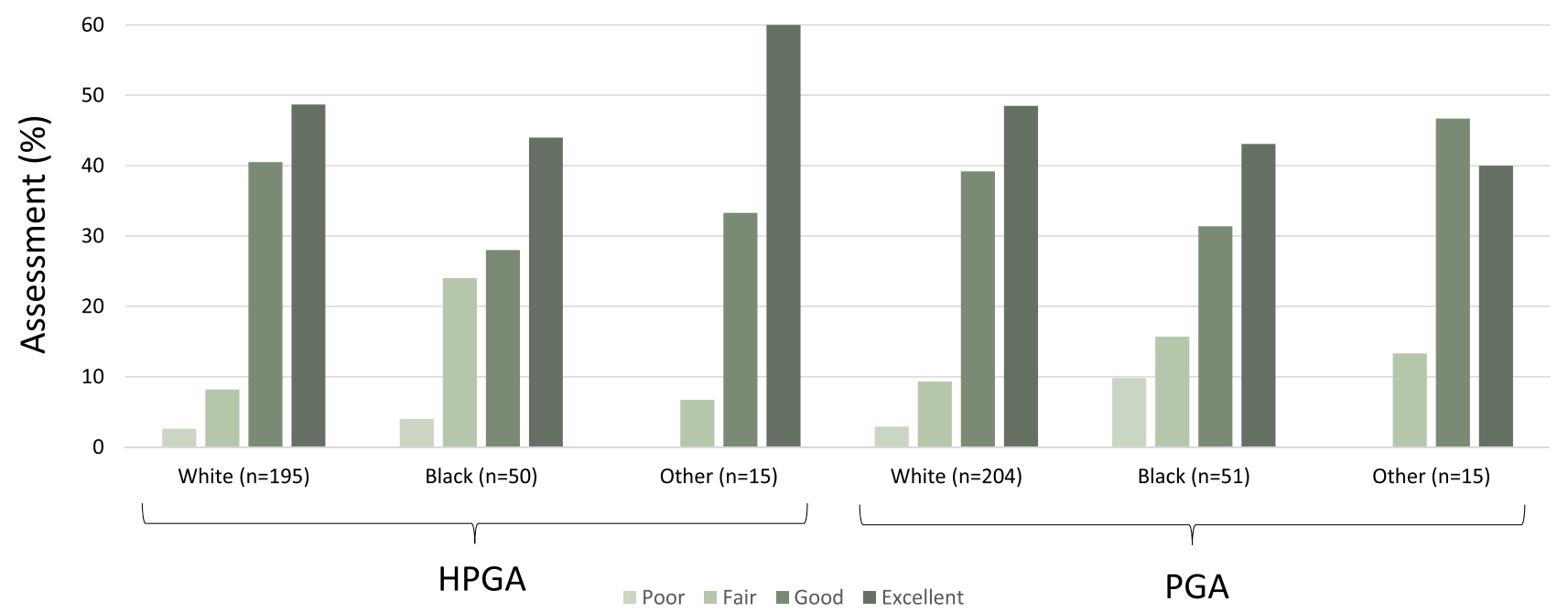

HPGA = healthcare professional global assessment; PGA = patient global assessment; there were no significant differences between groups for HPGA or PGA

Figure 4 Effect of race on HPGA and PGA.

Note: There were no significant differences between groups for HPGA or PGA.

Abbreviations: HPGA, healthcare professional global assessment; PGA, patient global assessment.

\section{Discussion}

Global satisfaction scores are a useful composite evaluation of efficacy and tolerability of an analgesic medication and can be considered as a more holistic assessment rather than focusing on only the pain intensity or pain relief scores often used in clinical trials (eg, summed pain intensity difference [SPID] or total pain relief [TOTPAR]). An analgesic providing high patient satisfaction may improve clinical outcomes and enhance healthcare provider-patient communication.
The current pooled analysis demonstrates that SST 30 mcg overall had high patient and healthcare professional satisfaction ratings throughout the postoperative and ED settings. Historically, a meta-analysis of analgesic trials have shown that patients tend to prefer patient-controlled analgesia (PCA) relative to conventional nurseadministered analgesia. ${ }^{26}$ However, a comparison study, which utilized the same PGA scale as the current study, demonstrated patients treated with an IV morphine PCA or 
Table 2 Effect of Age Group on Adverse Events

\begin{tabular}{|l|c|c|c|}
\hline Adverse Event & $\begin{array}{c}<65 \text { Years } \\
(\mathbf{n = 2 8 9})\end{array}$ & $\begin{array}{c}\geq 65 \text { Years } \\
(\mathbf{n = 3 4 )}\end{array}$ & $\begin{array}{c}\text { Total } \\
(\mathbf{n = 3 2 3})\end{array}$ \\
\hline At least I AE Reported & $94(32.5 \%)$ & $10(29.4 \%)$ & $104(32.2 \%)$ \\
Nausea & $66(22.8 \%)$ & $8(23.5 \%)$ & $74(22.9 \%)$ \\
Headache & $14(4.8 \%)$ & $2(5.9 \%)$ & $16(5.0 \%)$ \\
Dizziness* & $8(2.8 \%)$ & $5(14.7 \%)$ & $13(4.0 \%)$ \\
Vomiting & $9(3.1 \%)$ & $1(2.9 \%)$ & $10(3.1 \%)$ \\
Pruritus & $5(1.7 \%)$ & $1(2.9 \%)$ & $6(1.9 \%)$ \\
Hypotension & $6(2.1 \%)$ & 0 & $6(1.9 \%)$ \\
Oxygen Saturation Decreased & $3(1.0 \%)$ & $2(5.9 \%)$ & $5(1.5 \%)$ \\
Somnolence & $3(1.0 \%)$ & $1(2.9 \%)$ & $4(1.2 \%)$ \\
\hline
\end{tabular}

Note: $* P=0.007$

Abbreviation: $A E$, adverse event.

Table 3 Effect of BMI on Adverse Events

\begin{tabular}{|l|c|c|}
\hline Adverse Event & $\begin{array}{c}<30 \mathbf{~ k g} / \mathbf{m}^{\mathbf{2}} \\
\mathbf{( n = 1 9 9 )}\end{array}$ & $\begin{array}{c}\geq \mathbf{3 0} \mathbf{~ k g} / \mathbf{m}^{\mathbf{2}} \\
\mathbf{( n = 1 2 0 )}\end{array}$ \\
\hline At least I AE Reported* & $75(37.7 \%)$ & $28(23.3 \%)$ \\
Nausea & $52(26.1 \%)$ & $21(17.5 \%)$ \\
Headache* & $14(7.0 \%)$ & $2(1.7 \%)$ \\
Dizziness & $11(5.5 \%)$ & $2(1.7 \%)$ \\
Vomiting & $8(4.0 \%)$ & $2(1.7 \%)$ \\
Pruritus & $4(2.0 \%)$ & $2(1.7 \%)$ \\
Hypotension & $6(3.0 \%)$ & 0 \\
Oxygen Saturation Decreased & $2(1.0 \%)$ & $3(2.5 \%)$ \\
Somnolence & $3(1.5 \%)$ & $1(0.8 \%)$ \\
\hline
\end{tabular}

Notes: $* \mathrm{P}<0.05$; three patients not reported for $\mathrm{BMI}$ due to lack of recorded height. Abbreviations: BMI, body mass index; $A E$, adverse event.

Table 4 Effect of Sex on Adverse Events

\begin{tabular}{|l|c|c|}
\hline Adverse Event & Male (n= | 45) & Female (n= I 78) \\
\hline At least I AE Reported* & $30(20.7 \%)$ & $74(41.6 \%)$ \\
Nausea* & $24(16.6 \%)$ & $50(28.1 \%)$ \\
Headache* & $1(0.7 \%)$ & $15(8.4 \%)$ \\
Dizzines** & 0 & $13(7.3 \%)$ \\
Vomiting & $4(2.8 \%)$ & $6(3.4 \%)$ \\
Pruritus* & 0 & $6(3.4 \%)$ \\
Hypotension* & 0 & $6(3.4 \%)$ \\
Oxygen Saturation Decreased & $2(1.4 \%)$ & $3(1.7 \%)$ \\
Somnolence & $1(0.7 \%)$ & $3(1.7 \%)$ \\
\hline
\end{tabular}

Note: $* \mathrm{P}<0.05$

Abbreviation: $\mathrm{AE}$, adverse event.

a transdermal fentanyl PCA had $77 \%$ and $74 \%$ of patients, respectively, rating their method of pain control as good or excellent. $^{27}$ The PGA scores from the SST 30 mcg studies herein show similarly high or even higher PGA scores, despite the fact that SST $30 \mathrm{mcg}$ was healthcare professional-administered instead of patient-controlled.
Table 5 Effect of Race on Adverse Events

\begin{tabular}{|l|c|c|c|}
\hline Adverse Event & $\begin{array}{c}\text { White } \\
(\mathbf{n = 2 3 8 )}\end{array}$ & $\begin{array}{c}\text { Black } \\
(\mathbf{n = 6 7 )}\end{array}$ & $\begin{array}{c}\text { Other } \\
\mathbf{( n = 1 8 )}\end{array}$ \\
\hline At least I AE Reported & $83(34.9 \%)$ & $17(25.4 \%)$ & $4(22.2 \%)$ \\
Nausea & $57(23.9 \%)$ & $14(20.9 \%)$ & $3(16.7 \%)$ \\
Headache & $14(5.9 \%)$ & $2(3.0 \%)$ & 0 \\
Dizziness & $11(4.6 \%)$ & $2(3.0 \%)$ & 0 \\
Vomiting & $10(4.2 \%)$ & 0 & 0 \\
Pruritus & $4(1.7 \%)$ & $2(3.0 \%)$ & 0 \\
Hypotension & $6(2.5 \%)$ & 0 & 0 \\
Oxygen Saturation Decreased & $2(0.8 \%)$ & $2(3.0 \%)$ & $1(5.6 \%)$ \\
Somnolence & $4(1.7 \%)$ & 0 & 0 \\
\hline
\end{tabular}

Note: There were no significant differences in AEs between groups. Abbreviation: $A E$, adverse event.

Although there were some slight differences within demographic groups, the high HPGA and PGA scores reported here strongly support efficacy and safety of SST $30 \mathrm{mcg}$ across a broad patient population, regardless of age, BMI, sex, or race. Importantly, these high satisfaction ratings were obtained in clinical trials which used minimal multimodal analgesics, since they were registration trials which were focused on assessing the safety and efficacy of SST 30 mcg. $^{24-26}$

The pooled HPGA, PGA, and safety analyses by demographic population provide a differentiated evaluation of the efficacy and safety of SST $30 \mathrm{mcg}$ than previous publications. ${ }^{24,25}$ Evaluating both of the global satisfaction ratings along with AEs across the demographic populations helps healthcare providers determine the suitability of SST $30 \mathrm{mcg}$ for specific patient populations. To simplify dosing, SST $30 \mathrm{mcg}$ is a single fixed-dosage strength regardless of patient age, and it is the interdosing interval that allows flexibility in dosing, with previous analysis showing that patients 65 years or older request dosing of SST $30 \mathrm{mcg}$ less often (every 4 hours) than younger patients (every 3 hours). ${ }^{24}$ Healthcare professionals rated both old and young patients alike with relatively high good or excellent scores. This may have been due to the relatively low rate of side effects for both age groups, with only one adverse event (dizziness) rating as statistically higher in the elderly. This may be because administration of SST $30 \mathrm{mcg}$ does not provide a rapid increase in plasma concentrations nor a high $\mathrm{C}_{\max }$ which occurs with IV bolus administration. ${ }^{19}$ As opposed to an IV bolus, sufentanil from the SST is absorbed over time from the sublingual depot into the plasma. This unique pharmacokinetic profile of SST avoids the IV rapid high peak plasma concentrations and changes a three-compartment model with IV 
sufentanil into a two-compartment model. ${ }^{19,28}$ Perhaps not surprisingly, when SST was evaluated in study SAP302 for impact on cognitive function in ED patients, no negative effect on cognition occurred as measured by the Six-Item Screener. ${ }^{23}$ Therefore, even though across the Phase III studies, the elderly underwent proportionally more orthopedic surgeries (which tend to be more painful than softtissue surgeries) than younger patients, healthcare professionals gave the elderly patients the highest percentage of "excellent" ratings for the global satisfaction (61\%), which likely may be due to the combination of pain control and drug tolerability.

SST $30 \mathrm{mcg}$ was also highly rated by both healthcare professionals and patients regardless of BMI. A population pharmacokinetic study of SST demonstrated that sufentanil clearance in heavy-weight patients increased only minimally $(0.5 \%$ increase per $\mathrm{kg}$, referenced to the median weight of $80 \mathrm{~kg}) .{ }^{19}$ While sufentanil is highly lipophilic (octanol:water partition coefficient of 1800:1), more than twice as lipophilic as fentanyl, it has a smaller volume of distribution, likely due to its high protein binding ( $>90 \%)$ which may minimize the impact of increasing BMI on clearance. ${ }^{9}$ Although there were slight increases in nausea, vomiting, and headache in patients $<30 \mathrm{~kg} / \mathrm{m}^{2}$, these are common opioid-related side effects which did not appear to affect satisfaction ratings by either the patient or the healthcare professional.

The slightly higher HPGA and PGA scores in males versus females may be due to the very low rate of adverse events in male patients. Only $21 \%$ of males experienced any SST-related AE compared to the more typical rate of $42 \%$ of female patients experiencing at least one AE. Females experienced more of the well-known opioid-related side effects like nausea, headache, dizziness, and pruritus. These data are consistent with the findings from studies of other opioids showing that female patients in general tend to experience more opioid-related AEs relative to males. ${ }^{29,30}$

The potential limitations of this analysis include the relatively smaller percentage of elderly patients and the fact that opioid-tolerant patients were not enrolled in any of these studies. These data highlight the efficacy and safety of SST in non-opioid tolerant patients, but additional evaluation of real-world data may be warranted in opioid-tolerant patients, as well as in larger numbers of elderly patients. Another limitation associated with the interpretation of these data is based on the fact that these scores were obtained in a controlled clinical trial environment. Because healthcare provider communication with patients is commonly associated with increased patient satisfaction scores, simply being in these clinical trials could have resulted in slightly higher patient global assessments. However, in general, the healthcare professional global assessments were largely consistent with the patient global assessments, suggesting minimal bias in patients treated with SST $30 \mathrm{mcg}$. Future study should focus on global satisfaction scores after treatment with SST $30 \mathrm{mcg}$ in real-world scenarios.

\section{Conclusions}

Overall, these data are consistent with the previously published data on the efficacy and safety of SST $30 \mathrm{mcg}$ treatment. None of the demographic analyses showed a subpopulation with substantially lower satisfaction in the global assessment scores. These findings further support the use of sublingual sufentanil in all patient types, regardless of age, BMI, sex, or race for the treatment of moderate-to-severe acute pain.

\section{Abbreviations}

AE, adverse event; ASA, American Society of Anesthesiologists; BMI, body mass index; ED, emergency department; IV, intravenous; HPGA, healthcare professional global assessment; MME, morphine milligram equivalent; PACU, post-anesthesia care unit; PCA, patientcontrolled analgesia; PGA, Patient global assessment; SPID, summed pain intensity difference; SST, sufentanil sublingual tablet; TOTPAR, total pain relief.

\section{Data Sharing Statement}

The data used to support the findings in this article have been provided in this manuscript.

\section{Ethics Approval and Informed Consent}

The study protocols, protocol amendments, and informed consent forms for the studies (NCT02356588, NCT02447848, NCT02662556) were provided by the study center's Institutional Review Board. The list of approving ethics committees and institutional review boards is available in Supplement 1. The studies were conducted in accordance with the United States Investigational New Drug regulations specified under 21 CFR 50, 54, 56, and 312; the International Conference on Harmonization Harmonized Tripartite Guideline for Good Clinical Practice; and the Guidelines of 
the Declaration of Helsinki, Finland, 1964 and its subsequent amendments. All patients provided informed consent.

\section{Acknowledgments}

Medical writing support (funded by AcelRx Pharmaceuticals, Inc.) was provided by Eric R. Kinzler, PhD of Neura Therapeutik of AcelRx who, on the behalf of the authors, developed the first draft based on an authorapproved outline and assisted in implementing author revisions throughout the editorial process.

\section{Author Contributions}

All authors made a significant contribution to the work reported, whether that is in the conception, study design, execution, acquisition of data, analysis and interpretation, or in all these areas; took part in drafting, revising or critically reviewing the article; gave final approval of the version to be published; have agreed on the journal to which the article has been submitted; and agree to be accountable for all aspects of the work.

\section{Funding}

The SST $30 \mathrm{mcg}$ studies were funded by AcelRx Pharmaceuticals and were also funded in part by the Clinical and Rehabilitative Medicine Research Program (CRMRP) of the US Army Medical Research and Materiel Command (USAMRMC) under contract no. W81XWH-15-C-0046 and no. W81XWH-11-1-0361. The authors did not receive financial support for the authorship and/or publication of this article.

\section{Disclosure}

DL and MJ received financial support for the conduct of the studies from AcelRx. DL reports grants from Avenue, Trevena, Heron, Pacira, Innocoll, Centrexion, Recro, Concentric, Skk, Regeneron, Ingengeneron, Merck, Veru, Sorrento, Redhill, Squeris, and Samumed, outside the submitted work. GS and PP are employees and shareholders of AcelRx Pharmaceuticals. The authors report no other conflicts of interest in this work.

\section{References}

1. Buvanendran A, Fiala J, Patel KA, et al. The incidence and severity of postoperative pain following inpatient surgery. Pain Med. 2015;16 (12):2277-2283. doi:10.1111/pme.12751

2. Sokoloff C, Daoust R, Paquet J, et al. Is adequate pain relief and time to analgesia associated with emergency department length of stay? A retrospective study. BMJ Open. 2014;4(3):e004288. doi:10.1136/ bmjopen-2013-004288
3. Pavlin DJ, Rapp SE, Polissar NL, et al. Factors affecting discharge time in adult outpatients. Anesth Analg. 1998;87(4):816-826. doi:10.1097/00000539-199810000-00014

4. McCaffery M, Pasero C. How to choose the best route for an opioid. Nursing. 2000;30(12):34-39; quiz 40. doi:10.1097/00152193200030120-00014

5. Miner JR, Moore J, Gray RO, et al. Oral versus intravenous opioid dosing for the initial treatment of acute musculoskeletal pain in the emergency department. Acad Emerg Med. 2008;15(12):1234-1240. doi:10.1111/j.1553-2712.2008.00266.x

6. Andersen G, Christrup L, Sjogren P. Relationships among morphine metabolism, pain and side effects during long-term treatment: an update. J Pain Symptom Manage. 2003;25(1):74-91.

7. Paramanandam G, Prommer E, Schwenke DC. Adverse effects in hospice patients with chronic kidney disease receiving hydromorphone. $J$ Palliat Med. 2011;14(9):1029-1033. doi:10.1089/jpm.2011.0103

8. Smith HS. The metabolism of opioid agents and the clinical impact of their active metabolites. Clin J Pain. 2011;27(9):824-838. doi:10.1097/AJP.0b013e31821d8ac1

9. Bernards CM. Clinical implications of physiochemical properties of opioids. In: Stein C, editor. Opioids in Pain Control. Cambridge, UK: Cambridge University Press; 1999.

10. Lotsch J. Pharmacokinetic-pharmacodynamic modeling of opioids. $J$ Pain Symptom Manage. 2005;29(5):S90-S103. doi:10.1016/j. jpainsymman.2005.01.012

11. Fentanyl citrate injection package insert; 2019. Available from: https://dailymed.nlm.nih.gov/dailymed/getFile.cfm?setid= aacf276b-e133-4199-ad3f-67b894744c04\&type=pdf. Accessed September 15, 2020.

12. Bailey PL, Streisand JB, East KA, et al. Differences in magnitude and duration of opioid-induced respiratory depression and analgesia with fentanyl and sufentanil. Anesth Analg. 1990;70(1):8-15. doi:10.1213/ 00000539-199001000-00003

13. Clark NJ, Meuleman T, Liu WS, et al. Comparison of sufentanil-N2O and fentanyl-N2O in patients without cardiac disease undergoing general surgery. Anesthesiology. 1987;66(2):130-135. doi:10.1097/ 00000542-198702000-00004

14. Mather LE. Opioids: a pharmacologist's delight! Clin Exp Pharmacol Physiol. 1995;22(11):833-836. doi:10.1111/j.1440-1681.1995. tb01945.x

15. Zhang J, Chen L, Sun Y, et al. Comparative effects of fentanyl versus sufentanil on cerebral oxygen saturation and postoperative cognitive function in elderly patients undergoing open surgery. Aging Clin Exp Res. 2019;31(12):1791-1800. doi:10.1007/s40520-019-01123-8

16. Scott JC, Cooke JE, Stanski DR. Electroencephalographic quantitation of opioid effect: comparative pharmacodynamics of fentanyl and sufentanil. Anesthesiology. 1991;74(1):34-42. doi:10.1097/ 00000542-199101000-00007

17. Sufentanil citrate injection package insert; 2019; Available from: https://www.accessdata.fda.gov/drugsatfda_docs/label/2019/ 019050s037lbl.pdf. Accessed October 30, 2020.

18. DSUVIA package insert; 2019; Available from: https://www.access data.fda.gov/drugsatfda_docs/label/2019/209128s003lbl.pdf. Accessed July 1, 2020.

19. Fisher DM, Chang P, Wada DR, et al. Pharmacokinetic properties of a sufentanil sublingual tablet intended to treat acute pain. Anesthesiology. 2018;128(5):943-952. doi:10.1097/ALN.000000000 0002145

20. Minkowitz HS, Singla NK, Evashenk MA, et al. Pharmacokinetics of sublingual sufentanil tablets and efficacy and safety in the management of postoperative pain. Reg Anesth Pain Med. 2013;38(2):131-139.

21. Minkowitz HS, Leiman D, Melson T, et al. Sufentanil sublingual tablet $30 \mathrm{mcg}$ for the management of pain following abdominal surgery: a randomized placebo-controlled, phase-3 study. Pain Pract. 2017;17(7):848-858. doi:10.1111/papr.12531 
22. Hutchins JL, Leiman D, Minkowitz HS, et al. An open-label study of sufentanil sublingual tablet $30 \mathrm{mcg}$ in patients with postoperative pain. Pain Med. 2018;19(10):2058-2068. doi:10.1093/pm/pnx248

23. Miner JR, Rafique Z, Minkowitz HS, et al. Sufentanil sublingual tablet $30 \mathrm{mcg}$ for moderate-to-severe acute pain in the ED. $\mathrm{Am}$ J Emerg Med. 2018;36(6):954-961. doi:10.1016/j.ajem.2017.10.058

24. Hutchins JL, Leiman D, Rafique Z, et al. Pooled dosing and efficacy analysis of the sufentanil sublingual tablet $30 \mathrm{mcg}$ across demographic subgroups for the management of moderate-to-severe acute pain. $J$ Perianesth Nurs. 2020;35(1):22-28. doi:10.1016/j. jopan.2019.08.009

25. Miner JR, Melson TI, Leiman D, et al. Pooled phase III safety analysis of sufentanil sublingual tablets for short-term treatment of moderate-to-severe acute pain. Pain Manag. 2019;9(3):259-271.

26. Ballantyne JC, Carr DB, Chalmers TC, et al. Postoperative patient-controlled analgesia: meta-analyses of initial randomized control trials. J Clin Anesth. 1993;5(3):182-193. doi:10.1016/09528180(93)90013-5
27. Viscusi ER, Reynolds L, Chung F, et al. Patient-controlled transdermal fentanyl hydrochloride vs intravenous morphine pump for postoperative pain: a randomized controlled trial. JAMA. 2004;291 (11):1333-1341. doi:10.1001/jama.291.11.1333

28. Gepts E, Shafer SL, Camu F, et al. Linearity of pharmacokinetics and model estimation of sufentanil. Anesthesiology. 1995;83 (6):1194-1204. doi:10.1097/00000542-199512000-00010

29. Cepeda MS, Farrar JT, Baumgarten M, et al. Side effects of opioids during short-term administration: effect of age, gender, and race. Clin Pharmacol Ther. 2003;74(2):102-112. doi:10.1016/S0009-9236(03) 00152-8

30. Schnabel A, Poepping DM, Gerss J, et al. Sex-related differences of patient-controlled epidural analgesia for postoperative pain. Pain. 2012;153(1):238-244. doi:10.1016/j.pain.2011.10.022

\section{Publish your work in this journal}

The Journal of Pain Research is an international, peer reviewed, open access, online journal that welcomes laboratory and clinical findings in the fields of pain research and the prevention and management of pain. Original research, reviews, symposium reports, hypothesis formation and commentaries are all considered for publication. The manuscript management system is completely online and includes a very quick and fair peer-review system, which is all easy to use. Visit http:// www.dovepress.com/testimonials.php to read real quotes from published authors. 